\title{
Model of Gun-missile Anti-tank Operational Efficiency based on Bidirectional Queuing Theory
}

\author{
H.L WANG \& Y. LI \& J. X HUO \& W. HE \\ Langfang campus of Nanjing artillery academy
}

\begin{abstract}
In modern anti-tank battle, to forefend the large scale assault of enemy armor forces aiming at import targets and areas, defense troops always adopts the way of multilayer deploying including vehicle tank defense missile, anti-tank cannon and terminal guided projectile. Based on queuing theory and anti-tank fighting theory, the bidirectional queuing theory model for gun-missile operational efficiency was presented, which was built to analyze the influence of some factors such as targets mobility, fighting distance, weapons number, and weather conditions on the operation efficiency. The application to emblematical campaign hypothesis and its difference compared with common queuing model was presented and showed its validity and practicability.
\end{abstract}

KEYWORD: Gun-missile; Anti-tank; Service Probability; Bidirectional Queue Theory

\section{INTRODUCTION}

In future anti-tank combat, a higher requirement was presented due to the complexity of the battlefield environment and advanced technology of hostile armored forces. Commanders must solve the problems such as the rational allocation of existing anti-tank firepower according to the insult strength and battlefield environment, and the target allocation decisions in the course of combat.

Both anti-tank combat and anti air raids process has the characters of the service process and can be described with queuing theory. Recently, many scholars studied the application of queuing theory in military systems such as anti-tank combat, air defense system operational process and the ship's air defense system, and accomplished some fruitful works [1-4]. However, these models did not consider the change of the service system in the course of combat caused by counterwork, and did not adjust the operational capability of the new system. Based on stochastic process theory and anti-tank combat theory, the combat effectiveness model compatible with the anti-tank combat process was established. Based on the model, the operational effectiveness of the combat scenario in which the vehicle-mounted anti-tank missiles and wheeled anti-tank assault guns construct the anti-tank defense system was computed, furthermore, weapon lose and other parameters with the troops and configuration changes was studied also.
Table 1. Margin settings for A4 size paper and letter size paper.

\begin{tabular}{|l|c|c|c|c|}
\hline \multirow{2}{*}{ Setting } & \multicolumn{2}{|c|}{ A4 size paper } & \multicolumn{2}{c|}{ Letter size paper } \\
\cline { 2 - 5 } & $\mathrm{cm}$ & inches & $\mathrm{cm}$ & inches \\
\hline Top & 1.2 & $0.47^{\prime \prime}$ & 0.32 & $0.13^{\prime \prime}$ \\
\hline Bottom & 1.3 & $0.51^{\prime \prime}$ & 0.42 & $0.17^{\prime \prime}$ \\
\hline Left & 1.15 & $0.45^{\prime \prime}$ & 1.45 & $0.57^{\prime \prime}$ \\
\hline Right & 1.15 & $0.45^{\prime \prime}$ & 1.45 & $0.57^{\prime \prime}$ \\
\hline All other & 0.0 & $0.0 "$ & 0.0 & $0.0 "$ \\
\hline Column width* & 9.0 & $3.54^{\prime \prime}$ & 9.0 & $3.54^{\prime \prime}$ \\
\hline Column spacing* & 0.7 & $0.28^{\prime \prime}$ & 0.7 & $0.28^{\prime \prime}$ \\
\hline
\end{tabular}

\section{A BIDIRECTIONAL QUEUING MODEL OF COMBAT CONFRONTATION PROCESS}

Weapons employed in anti-tank positions include vehicle-mounted anti-tank missile systems with long-range, high precision and low firing rate, as well as wheel anti-tank cannon with faster firing rate, short-range and lower precision. Different weapons constructed the anti-tank defense system. The short-range defense system works while the long-rang defense system are broken. The anti-tank combat process is a team of customer receiving tandem Desk (our anti-tank weapon system) service (enemy armored targets) according to queuing theory, when a service can not meet customer needs or the customer service does not happen, customer enters the next service process. However, it is worth noting that these customers (enemy armored targets) 
in the process of receiving services or before receiving services will try their best to suspend or delay the time of service by taking the confrontational strategy, their goal is to reduce the efficiency of the service.

\subsection{Basic assumptions}

Firstly, initial conditions such as force number and distance of both sides in the confrontation process will not changed once determined, and both sides will take its advantageous strategy all the time.

Secondly, other factors will not be taken into account, that means the commanding officers of both sides can command their combat units smoothly and choose a favorable target to combat.

Thirdly, time for weapon system to complete an attack is random variables related to the distance and weapon characteristics.

\subsection{Mathematical model}

\subsubsection{The basic queuing model of the confrontation process}

Confrontation process between Anti-tank weapons and armored targets can be seen as a process similar to multi-Desk parallel system work process. Armored targets enter the anti-tank defensive positions with rate $\lambda$, we can get

$$
\begin{gathered}
P_{0}= \begin{cases}\frac{1}{\sum_{k=0}^{c} \frac{(c \rho)^{k}}{k !}+\frac{c^{c}}{c !} \frac{\rho\left(\rho^{c}-\rho^{N}\right)}{1-\rho}}, \rho \neq 1 \\
\frac{1}{\sum_{k=0}^{c} \frac{c^{k}}{k !}+\frac{c^{c}}{c !}(N-c)}, \quad & \rho=1\end{cases} \\
P_{n}= \begin{cases}\frac{(c \rho)^{n}}{n !} P_{0}, & 0 \leq n \leq c \\
\frac{c^{c}}{c !} \rho^{n} P_{0}, & 0 \leq n \leq N\end{cases}
\end{gathered}
$$

Where: $\rho$ is the service efficiency of the service system. $\lambda$ is arrival rate, which equals to the average arrival rate per unit time of armored targets appear in antitank positions defense zone. $\mu$ is service rate, the average number of serviced customers per unit time. $\mathrm{c}$ is the total number of weapons systems in positions (Desk number). $\mathrm{N}$ is system capacity (the largest armored targets quantity of per unit time can be serviced of the system).

Obviously, according to stochastic process theory, the probability of armored targets break into defensive position should be:

$$
P_{t}=\frac{c^{c}}{c !} \rho^{N} P_{0}
$$

The service probability of service system consisted of one defense line is:

$$
P_{f}=1-P_{t}
$$

In actual combat, armored vehicles will take a smokescreen as photoelectric interference once being attacked and approach to its targets as soon as possible to take advantage of its fast firing rate and good protection capability to fight back. Therefore, the counterattack process can also be analyzed with the queuing theory, the difference is anti-tank weapons in the attack range as customers, and armored vehicles as service system.

\subsubsection{Bidirectional queuing service model}

(1) Bidirectional queuing service model

Assume a period the warring sides A, B, and Aside arms unit number is $C_{A}$, has the target capacity of $N_{A}$, the average service rate is $\mu_{A}$. The B-side arms unit number is $C_{B}$, has the target capacity of $N_{B}$, the average service rate is $\mu_{B}$.

The service rate of the two sides should be gained as the formula (5) below:

$$
P_{0 A}=\left\{\begin{array}{l}
\frac{1}{\sum_{k=0}^{c_{A}} \frac{\left(c_{A} \rho_{A}\right)^{k}}{k !}+\frac{c_{A}{ }^{c_{A}}}{c_{A} !} \frac{\rho_{A}\left(\rho_{A}{ }^{c_{A}}-\rho_{A}{ }^{N_{A}}\right)}{1-\rho_{A}}}, \rho_{A} \neq 1 \\
\frac{1}{\sum_{k=0}^{c_{A}} \frac{c_{A}{ }^{k}}{k !}+\frac{c_{A}{ }^{c_{A}}}{c_{A} !}\left(N_{A}-c_{A}\right)}, \quad \rho_{A}=1
\end{array}\right.
$$$$
P_{f A}=1-\frac{c_{A}^{c_{A}}}{c_{A} !} \rho_{A}{ }^{N_{A}} P_{0 A}
$$$$
\rho_{A}=\frac{\lambda_{B}}{c_{A} \mu_{A}}=\frac{c_{B}}{c_{A} \mu_{A} \Delta T}
$$

$P_{0 B}=\left\{\begin{array}{l}\frac{1}{\sum_{k=0}^{c_{B}} \frac{\left(c_{B} \rho_{B}\right)^{k}}{k !}+\frac{c_{B}^{c_{B}}}{c_{B} !} \frac{\rho_{b}\left(\rho_{B}^{c_{B}}-\rho_{B}^{N_{B}}\right)}{1-\rho_{B}}}, \rho_{B} \neq 1 \\ \frac{1}{\sum_{k=0}^{c_{B}} \frac{c_{B}{ }^{k}}{k !}+\frac{c_{B}{ }^{c_{B}}}{c_{B} !}\left(N_{B}-c_{B}\right)}, \quad \rho_{B}=1\end{array}\right.$

$P_{f B}=1-\frac{c_{B}^{c_{B}}}{c_{B} !} \rho_{B}{ }^{N_{B}} P_{0 B}$

$\rho_{B}=\frac{\lambda_{A}}{c_{B} \mu_{B}}=\frac{c_{A}}{c_{B} \mu_{B} \Delta T}$

The above formula, $\Delta T$ is the time period for the calculation, while both sides has different 
weapons, $\mu_{A}, \mu_{B}$ can be calculated separately after the target allocation and integrated, or solved as the average service rate with equation (6) according to reference [3].

$$
\mu=\frac{1}{\sum_{i=1}^{n} C_{i}} \sum_{i=1}^{n} C_{i} \mu_{i}
$$

(2) Lose of both sides determined according to bidirectional queuing service model

According to the current status quo of our antitank weapons, combat process can be assumed as follows: After the fighting broke out, remote antitank weapons works and fire against the armored vehicles before they impact to the distance that they can fire back. Once armored vehicle break through the first defence, they will fight against anti-tank weapons, then the damage factors of both sides should be taken into account while computing the operational efficiency. Efficiency of stage before confrontation can be solved by general queuing service model, while in case of confrontation, a bidirectional queuing service model can be used to compute the efficiency. The hit possibility and single damage of the weapon system are used to determine the damage in the service process. accumulation of the damage in various stages is overall damage.

In stage of confrontation, it is necessary to compute the weapons number of both sides to compute the operational efficiency. Each side act as service units while take other side as customers and solve the corresponding service probability. The service probability determines the mutilating probability, and the mutilating probability determines the change of weapons number of both sides.

In some stage, we assume the number of a certain type weapon is $c_{i}$, the service probability of other side is $P_{f i}$, the hit probability of the other side is $P_{h i}$, damage probability of the other weapons systems is $P_{d i}$, the number of damage of a certain type weapon can be determined as follows:

$$
\Delta c_{i}=c_{i} \cdot P_{f i} \cdot P_{h i} \cdot P_{d i}
$$

\section{SIMULATION AND ANALYSIS}

\subsection{Operation plans}

The anti-tank combat weapons in defensive positions are consisted of two weapons: a vehiclemounted anti-tank missile company (including 4 anti-tank missile vehicle), a certain type of wheeled anti-tank assault gun company (including 9 anti-tank vehicle). The weapons performance parameters are shown in Table 1. The hostile side have 10 armored vehicles, including four M1A1 tanks equipped with $120 \mathrm{~mm}$ howitzers, 6 LAV-AT Light Armored Vehicle, equipped with TOW2B anti-tank missiles. Both sides ammunition characteristics shown in Table 1.

Tab. 1 Parameters of weapons

\begin{tabular}{|c|c|c|c|c|}
\hline Items & $\begin{array}{c}\text { Range } \\
(\mathrm{m})\end{array}$ & $\begin{array}{c}\text { Hit probability } \\
(\%)\end{array}$ & $\begin{array}{c}\text { Speed } \\
(\mathrm{m} / \mathrm{s})\end{array}$ & $\begin{array}{c}\text { Fire intervals } \\
(\mathrm{s})\end{array}$ \\
\hline $\begin{array}{c}\text { Anti-tank } \\
\text { missile }\end{array}$ & $800-5000$ & 90 & 20 & $12-20$ \\
\hline \multirow{2}{*}{$\begin{array}{c}\text { Anti-tank } \\
\text { assault } \\
\text { gun }\end{array}$} & $200-4000$ & $\begin{array}{c}\text { Guided } \\
\text { projectile: } 80\end{array}$ & 25 & 20 \\
\cline { 3 - 3 } & & $\begin{array}{c}\text { Common } \\
\text { projectile: } 40\end{array}$ & 4 \\
\hline M1A1 & $300-4000$ & 40 & 15 & 4 \\
\hline LAV-AT & $200-3850$ & 80 & 20 & $15-20$ \\
\hline
\end{tabular}

Operation is in the daytime and terrain is in the open land of the plains, the initial distance between two sides is $6000 \mathrm{~m}$.

\subsection{Simulation and results}

The anti-tank missile can attack the armored vehicles freely only in the 4000-5000m when armored vehicles approach at constant speed from a $6000 \mathrm{~m}$ distance to the defensive positions, . The armored vehicles will be able to attack the anti-tank missile after breaking through the line of defense, and come into the range of wheeled assault guns.

It will take about 66s for M1A1 to pass through 4000-5000m area, as for LAV-AT, it will take about 50s. To simplify the processing, customer flow $\lambda$ is assumed to be $10 / \mathrm{min}$. Desk at this stage is the 4 anti-tank missiles, with target capacity 8 . Taking into account the communication and coordination ability, its service rate is assumed to be $2 / \mathrm{min}$, rather than theoretical $3 / \mathrm{min}$. According to 2.2 department, the probability can be obtained:

$P_{f m}=0.72, \quad P_{t m}=0.28$.

Obviously, during this period, seven armored vehicles was shoot by the anti-tank missiles, according to the accuracy and damage capacity of anti-tank missile, the armored vehicles destroyed can be assumed 6. M1A1 tanks should to be the key target because of its treat to the anti-tank, so the hostile armored vehicle damage is four M1A1 tanks and $2 \mathrm{LAV}$-AT tank destroyer.

The remaining four armored vehicles will fight against anti-tank weapons after traveling to distance between $3000-4000 \mathrm{~m}$, due to its advanced fire control performance and a faster rate of fire, a separate confrontation with anti-tank missiles will cause greater damage to anti-tank missile. The anti- 
tank missile should retreat to the far distance to combat when the wheel anti-tank assault gun has advantage in number and condition.

Combat between wheeled anti-tank guns and enemy armor can be described with the bidirectional queuing service model, the process is as follows:

According to the bidirectional queuing service model, 9 anti-tank assault guns are the service desk, with target capacity of 9 and its artillery missiles hit probability of 0.8 . It will use about 2 rounds to destroy an armored target. To the Shells with hit probability of 0.4 , It will use about 4 rounds to destroy an armored target. The services rate are $1.5 \mathrm{pm}$ and $4 \mathrm{pm}$. Two transmit mode has the same probability, which can be obtained by 1.2:

$$
P_{f c}=1, \quad P_{t c}=0
$$

In the case of superior force and prepared, 9 wheeled antitank assault guns has an absolute advantage against four armored vehicles with the same firepower and rate of fire, all the armored vehicles will be hit by anti-tank assault guns.

When four light armored vehicles act as service desk, on account of TOW anti-tank missiles having the ability of shooting in traveling and more powerful, it can destroy a wheeled assault guns with 2 rounds, and service rate was $2 / \mathrm{min}$. the service probability is $P_{f c}=0.45$.

Tab. 2 Results compared between single queuing model and bidirectional queuing service model

\begin{tabular}{|c|c|c|c|c|c|}
\hline \multicolumn{2}{|c|}{ Items } & \multicolumn{2}{c|}{ Course 1 } & \multicolumn{2}{c|}{ Course 2 } \\
\cline { 3 - 6 } & & Single model & Bidirectional model & Single model & Bidirectional model \\
\hline \multirow{2}{*}{ Service Probabi-lity } & Anti-tank weapon & 0.72 & 0.72 & 1 & 1 \\
\cline { 2 - 6 } & Armored vehicle & 0 & 0 & 0 & 3 \\
\hline \multirow{2}{*}{ Lose } & Anti-tank weapon & 0 & 0 & 4 & 4 \\
\cline { 2 - 6 } & Armored vehicle & 6 & 6 & 4 \\
\hline
\end{tabular}

\subsection{Analysis of simulation results}

In scenario, the open area of the battle is helpful for the anti-tank missiles to take its long-range precision strike capability as a considerable advantage, even if the weapon number is not dominant. When the hostile armored vehicles break through in the range of anti-tank missile defense with its numerical superiority, anti-tank assault guns equipped with artillery missiles can also fight back effect in the far distance, but due to the same strike capability of the armored vehicles, it will suffer a certain amount of damage.

To some extent, bidirectional queuing service mode considers the initiative of both sides and is in line with the actual situation of confrontation combat.

\section{CONCLUSION}

Bidirectional queuing service model presented in this paper is more suitable and in line with the factual battle for solving the loss of both sides in the confrontation process. The contrast with the single queuing model simulation results showed that the new model reflects the confrontation condition better under the anti-tank combat process.

\section{REFERENCES}

[1] Lu Jianwei, Tang Songjie, Li Lei. 2007. Missile and artillery combined probability analysis of multi-layer air defense system. Firepower and command and control, 32 (12):66-68, 72 .

[2] Road Jianwei, Kang Xiao. 2008. I like the service probability of ship to air missile based on improved queuing theory. Electro-optical and Control, 15(6):66-70.

[3] Zheng Chunbo,Lu Xiaoqiang,Kang Yongwen. 2009. Surface-to-air missile system operational evaluation of queuing theory. Ship Electronic Engineering, 29(9):47-49.

[4] Guo Jianliang, Gao Xin, Shen Maoxing. 2009. The multilayer intercept cruise missiles efficiency based on queuing theory analysis $\mathrm{A}$ ir Force Engineering University (Natural Science), 10 (5):37-40 [4]. 